\title{
A call for action from workers, local residents, and consumers: a safe society from toxic chemicals
}

\author{
Shinbum Kim ${ }^{1}$, Sanghyuk $\operatorname{Im}^{1}$, Youngeun $\mathrm{Choi}^{1}$, Soomi Park ${ }^{1}$, Jaesoon Hyun ${ }^{1}$, Kyung Seok Lee ${ }^{2}$, \\ Sunimm Lee ${ }^{3}$, Sung-nan Lee ${ }^{3}$, Jeongri Seo ${ }^{3}$, Ju Hee Kim ${ }^{4}$, Hyunsun $\mathrm{Na}^{5}$, Minsun $\mathrm{Kim}^{6}$; \\ Korean Society for Environmental Health and Toxicology; Korean Society for Occupational \\ and Environmental Medicine; Korean Industrial Hygiene Association; Korean Academic \\ Society of Occupational Health Nursing; Association of Physicians for Humanism; Korean \\ Pharmacists for Democratic Society; Korean Dentists for Democratic Society and the \\ Association of Korea Doctors for Health Rights \\ ${ }^{1}$ Wonjin Institute for Occupational and Environmental Health, Seoul; ${ }^{2}$ Citizens' Movement for Environmental Justice, Seoul; \\ ${ }_{3}^{3}$ COOP Consumer Co-operative, Seoul; ${ }^{4}$ Korea Women Environment Network, Seoul; ${ }^{5}$ Korean Metal Workers' Union, Seoul; \\ ${ }^{6}$ Seoul Food Education Network, Seoul, Korea
}

\section{Introduction}

In 2016, it was revealed that many children and pregnant women had been injured or killed by disinfectants for home humidifiers in South Korea (hereafter Korea). Criminal trials against the companies that manufactured, imported, or sold such products are now under way and a consumer boycott against them has gained widespread public support, however, more fundamental changes toward a society that is safe from toxic chemicals have yet to be achieved.

In this context, a group of experts and non-governmental organization (NGO) activists gathered to diagnose the current conditions of controls over toxic chemicals in Korea, and to propose policy alternatives. Based on a series of discussions, a consensus report was drafted by Shinbum Kim, a researcher of the Wonjin Institute for Occupational and Environmental Health. The draft was revised several times with comments from professional communities. The final version was endorsed by representative professional associations including the Korean Society for Environmental Health and Toxicology, the Korean Society for Occupational and Environmental Medicine, the Korean Industrial Hygiene Association, the Korean Academic Society of Occupational Health Nursing, and 549 healthcare professionals affiliated to NGOs such as the Association of Physicians for Humanism. On July 11, 2016, the agenda was finally released to the public.

\section{What Is a "Toxic Chemical-free Society"?}

The Constitution of the Korea stipulates that the state has a responsibility to guarantee the nation's safety, freedom, and welfare by helping people do their duty and undertake responsibilities concomitant to freedom and rights. Here, a question arises: Is our society safe? Various hazards have become widespread in our daily lives, as a result of industrialization and scientific innovation. Meanwhile, by virtue of dissemination of knowledge and scientific development, people have become more aware of the causes of hazards that were not known previously. People have realized, in particular that hazards potentially harmful to our health and life, have been brought to us without disclosure of such information, or our consent.

Workers, local residents and consumers demand a society that is safe from toxic chemicals, for us and our future generations.

\section{Why 2025?}

Currently, many chemicals are being used in homes, workplaces, and other areas. As well-known carcinogenic substances are still used in Korea, we concluded that we must urgently reach a social consensus on the use of toxic chemicals. In 2002, the international society established the Strategic Approach to International Chemicals Management (SAICM) to promote chemi- 
cal safety around the world, aiming to produce and use chemicals in ways that minimize significant adverse impacts on human health and the environment by 2020. In response to such a resolution by the global community, we have established a period of 10 years to term the maximum effort into a safe society from toxic chemicals.

\section{Diagnosis: Current Conditions}

Is Korean society safe from toxic chemicals? We can definitely say "no", for the following reasons.

Humidifier disinfectant accidents and asbestos: contaminated baby powder accident.

- Safety information is incompletely disclosed to the public.

- Chemicals are used without verification of their toxicity and advised use.

- Chemical companies can easily evade their responsibility if they claim to be unaware of toxicity.

- Reversed responsibility is the rule, requiring victims to prove harm caused by products.

- Each individual has to bear the burden of damage brought by the products.

Half of all chemicals used in the manufacturing industry contain carcinogens or substances with reproductive toxicity.

- Our society overuses toxic materials.

- Prevention or protective measures against occupational cancer are not sufficient.

- Workers are denied the right to know the harmful effects of chemicals used in workplaces.

Environmental accidents such as hydrofluoric acid leakage incidents have been repeated.

- Safety is not guaranteed by the government or employers.

- The rights of local residents to know about safety is denied.

- There are no reliable preventive measures against chemical accidents.

Up to $66 \%$ of the information about products is classified as trade secrets.

- The contention of 'trade secrets' is indiscriminately used.

- Exposure of consumers and workers to chemicals is not informed accurately.

- Inaccurate information is often disseminated.

Childhood cancers, asthma, and other developmental disorders have increased.

- There is a lack of vision about passing a safe society to the fu- ture generation.

- We bear a double burden due to known-but-not-prohibited toxic materials and to unknown hazards such as environmental hormones and persistent organic pollutants.

- The unequal distribution of risks - social minorities and the disadvantaged population are more vulnerable to toxic chemicals - should be considered.

There is lack of transparency and reliability in policy making process.

- Participation of workers, local residents, and consumers in policy making processes is insufficient.

- There are not enough professionals with expertise in dealing with chemical safety issues.

- There is no reliable process for managing chemical-related accidents.

\section{Diagnosis: Prospects}

Can we dream of a better society under these poor circumstances? We bravely say, "yes”, on the grounds described below.

\section{People's awareness has risen, due to the Sewol ferry disaster} and various chemical accidents in recent years.

- People have come to realize that a safe society cannot be achieved by delegating safety affairs solely to the government and corporations.

- People have come to understand that workers, local residents, and consumers themselves should monitor the measures provided for their own safety, and that they should play a more active role towards a safer society as a whole.

\section{Empowerment of civic society and labor unions.}

- Civic society has recognized that a wide range of organizations, such as consumer associations, community organizations, labor unions and various advocacy groups which involve health, environmental, child protection, and animal rights should all act together against common threats and hazards.

- More groups have recognized safety issue as part of their own agenda.

- More opportunities have been made for joint learning and shared vision across various civic groups.

New trends in the global community have a positive influence on Korean society.

- The European Union implemented the Registration, Evaluation, Authorization and Restriction of Chemical (REACH) regulation in 2007, stipulating that no substance can enter 
the market without disclosing information about its toxicity and usage, and that corporations should be responsible for proving safety, which is creating a positive atmosphere to construct regulations about dangerous chemicals in each country

- International cooperation has been expanded for a safer society from toxic chemicals, such as the establishment of SAICM.

\section{$\mathrm{K}-\mathrm{REACH}$ and CCA were legislated.}

- The Registration and Evaluation of Chemical Substances (KREACH) act came into effect in 2015, aiming to create a system similar to the EU's REACH.

- The Chemicals Control Act (CCA) also came into effect in 2015 , to protect a community's right-to-know in responses to, and prevention measures against, chemical accidents.

\section{How Can We Make a Society That Is Safe From Toxic Chemicals?}

There are certain principles that the government, corporations, and citizens must all abide by in order to make society safe from toxic chemicals. As information about chemical substances is incomplete, decision-making can be difficult. If we comply with basic principles, we will be able to make sound judgments. The Precautionary Principle agreed by international society should be practiced in Korea as follows.

Corporations should be accountable for verifying the safety of their chemical products.

Those who sell products containing chemicals must bear responsibility for any harm caused by the products. Taking preventive measures against potential harm is essential. Corporations should inform consumers about potential harm caused by their products by investigating the toxicity of the chemicals. If the toxicity or use of the chemicals is not defined, the product should be prohibited from sale. Consumers have a right to know about the products they consume, and the producers should verify their safety.

Priority should be given to the precautionary principle in situations of uncertainty.

In a situation where there is not enough evidence or it is conflicting, the precautionary principle should be applied. Uncertainty regarding the potential harm of chemicals indicates that there is not enough evidence to guarantee its safety. Corporations, not citizens, should be held liable in such situations.

The precautionary principle should be applied in all stages of the process, including introduction, management, and disposal of chemical substances. Special measures to protect vulnerable populations, such as children and pregnant women should be included in the legislation.

\section{Principlesin managing chemical-related accidents.}

Information about chemical-related accidents should be disclosed immediately, and the participation of NGOs and local communities in the work process should be guaranteed by law.

\section{Transparency and reliability of chemical safety policy should} be secured.

The government should obtain credibility on policies regarding chemical safety, and such reliability relies on transparency. The European Chemicals Agency is famous for its successful communication, and the Korean government should consider adopting their communication strategy and stakeholder policy by modifying the platform for Korea's situation. People's rightto-know and right-to-be-informed should be assured. A policy process in drawing people's informed consensus about whether or not to accept the level of risk should be established.

NGOs should be able to independently produce and disseminate information.

In many cases, information disclosed by the government and corporations is not friendly to workers, local residents, or consumers. The information should be consolidated and edited appropriately according to its goal, and delivered effectively. For this purpose, NGOs should operate an information center. NGOs should produce and disclose data to inform the people appropriately.

Inequality caused by information asymmetry should be tackled.

When people know, they act to avoid risks. Thus, right-toknow should be realized at all levels. Inequality that derives from unequal access to information should not affect the decisionmaking process regarding the level of risk.

Trade secrets should not be abused: four principles regarding trade secrets.

The first principle is proving appropriate reasons and obtaining permission in advance for confidentiality. Secrets can be permitted when they are proven worthy. The government grants permission, and those who wish to maintain the secret should prove its need. Documents used to verify the secrecy must be stored for a certain period of time, and should be disclosed for verification if necessary.

The second principle is the distinction between confidentiali- 
ty and non-disclosure. In fact, only the identity of chemicals (name and identification number) is regarded as confidential, and all other information is regarded as non-disclosure, not confidential. Confidential information can be defined for a certain amount of time, however, non-disclosed information can be disclosed depending on the situation. Non-disclosed information should not be regarded as confidential.

The third principle is forbidding confidentiality on toxic chemicals. The confidentiality of information should be respected, but it should not harm any person or the environment. Except for chemicals that cause only temporary harm which will heal quickly, every substance of very high concern (SVHC), chemicals that are carcinogenic, mutagenic or toxic to reproduction (CMR), persistent, bio-accumulative and toxic (PBT), and very persistent, very bio-accumulative (vPvB) substances should not be permitted as corporate confidential information.

The fourth principle is a restriction on the duration of confidentiality. The confidentiality of a product should only be allowed with proper reporting to the government, and the government should keep the secret information until its expected disclosure. Extension of the confidentiality can be allowed for one term with an appropriate reason, but it should pass a proper review for permission of extension.

\section{Vision and Target for 2025}

A vision for a toxic chemical-free society until 2025: creating a toxic chemical-free society for now and future.

- We are living in a society with increasing use of toxic chemicals, and are facing the consequences.

- Health problems associated with toxic chemicals are increasing. Health hazards to the vulnerable population and children are especially serious, such as attention deficit/hyperactivity disorder, precocious puberty, fetal malformation, and cancer.

- Our inclination for more comfort is changing the human lifestyle, which could lead to consequences that are negative both economically and socially.

- Fundamentally, we claim a toxic chemical-free society. Use of toxic chemicals should be minimized, and strict management of chemicals is required, admitting the limitations of existing technologies.

- To assure a toxic chemical-free society, the participation of civic society, as well as the government and corporations, is required in decision making, and efforts for guaranteeing transparency should be followed.

- It takes long time to identify the potential harm of chemicals, and to observe actual damage. Verifying causal associations between chemicals and health is even more challenging. The current problems will have consequences for the future gen- eration. For the safety of future generations as well as the current one, establishing a toxic chemical-free society is urgent.

Objectives for a toxic-chemical free society in 2025.

- Full-fledged efforts for developing substitute materials and reducing the use of toxic chemicals should be made.

- The right to know and a remediation of information asymmetry should be realized.

- Corporations should be made fully accountable for the safety of toxic chemicals.

- Systematic management systems for toxic chemicals should be established.

- Environmental justice should be realized for the vulnerable population.

- Civic society should be able to participate in policy making processes.

- An independent chemical information center, operated by NGOs, should be established.

\section{Detailed Targets for Objectives}

Full-fledged efforts for developing substitute materials and reducing the use of toxic chemicals should be made.

- A roadmap to reduce and replace highly toxic chemicals, and action plans to develop substitute materials should be made.

- This requires make a list of highly toxic chemicals, and a create positive atmosphere.

- Technical, economical, and administrative support for developing substitute materials should be provided, and infrastructure for sharing information should also be established.

\section{Right to know and remediation of information asymmetry} should be realized.

- The right of citizen to know is the foremost principle. Harm caused by information asymmetry should be prevented.

- In order to guarantee a citizen's right to know over trade secrets, four principles regarding trade secrets should be applied to the Trade Secret Council in the Ministry of Environment.

- Consumers have the right to know about the toxic chemicals used and included in products, and workers have the right to know about toxic chemicals used in their workplace. An obligation for companies to label toxic chemicals should be strongly enforced.

- To ensure a community's right to know, the amount of toxic chemicals emitted, transferred, and used should be officially announced. In the event of toxic chemical related accidents or damage, a community's right to participate in the investigation and further development of preventive measures 
should be guaranteed.

- To remedy information asymmetry, infrastructure to ensure people's access to relevant information should be established in advance. Information such as a list of SVHCs/regulatory information from other countries related to toxic chemicals/ information about alternative materials and technologies should be easily accessible by both citizens and corporations.

\section{Corporations should be made to be fully accountable for the} safety of toxic chemicals.

- In principle, the responsibility to verify the safety of chemicals and to manage them safely rests with corporations. The government should recognize this and develop institutional support.

- Corporations have a responsibility to verify the safety of chemicals according to their use and exposure scenarios. Legal procedures for penalizing false or defective reports should be established.

- Harm caused to consumers by toxic chemicals in products and occupational injuries/diseases or chemical incidents in communities should be attributed to corporations. Institutional support for thorough investigation and stronger punishment should be provided.

A systematic management system for toxic chemicals should be established.

- To comply with the precautionary principle, the toxicity and usage of all chemicals in products must be assessed before sale on the market. Materials without toxicity information should not be used in any process.

- Reasonable standards to manage chemicals should be prepared. The priority should be given to SVHC chemicals including $\mathrm{CMR}, \mathrm{PBT}$ and $\mathrm{vPvB}$ substances.

- The classification of toxicity, not an arbitrary decision, should be a guiding rule for the management of chemicals. Unification of the classification system by law is required.

- When a highly toxic substance is identified, societal efforts should be taken, with the idea of candidate materials for substitution.

Environmental justice regarding vulnerable population should be realized.

- Information about even the smallest amount of toxic chemicals, which are more likely to affect the vulnerable population, should not be omitted. Exposure standards should be devised and applied, considering people's socioeconomic conditions, age, and other characteristics.

- Information about chemicals, irrespective of secrecy, should be disclosed to workers who directly use them in their workplace, and support to comply with chemical safety measures in the workplace should be offered.

- Environmental impact assessments regarding children, pregnant women, and other vulnerable populations should be performed before the establishment of a manufactory. Such results should be taken into account when locating firms near children's playgrounds or housing areas.

- Standards for children's products should be strengthened for the sake of the future generation's safety; the scope of 'children's products' should be expanded to include products that children use daily.

- An Environmental Liability Act regarding the vulnerable population should be prepared, and additional social efforts such as support for victim's litigation are needed to ensure environmental justice.

\section{Civic society should be able to participate in policymaking} processes.

- Targets and specific plans for reducing/substituting toxic chemicals should be made through consensus of government, corporations, and civic society.

- Communication strategies to facilitate consensus among stakeholders should be developed. The opinions of each stakeholder should be gathered and considered in policy making.

- The participation of stakeholders in planning should become an obligation. Meaningful communication and transparency of process should also be assured.

Independent chemical information centers operated by NGOs should be established

- Information related to toxic chemicals should be consolidated and edited appropriately according to its goals, and delivered effectively.

- Independent information centers operated by NGOs should be established, which will produce and disclose relevant information according to $\mathrm{K}-\mathrm{REACH}$ and the CCA.

- To tackle the resource gap between corporations and civic society, budgetary support for independent NGO centers should be provided.

- To make a Green Chemical Center, as stipulated by KREACH, not only support to corporations but also to act to protect citizen's health and the environment, the government should consider allowing NGOs to apply for the scheme.

\section{Institutional Improvement Needed}

We demand laws to protect people's lives and a healthy envi- 
ronment. Undoubtedly, our efforts to create a legitimate law would prove fruitful. A legitimate law is defined below.

\section{All usage and toxicity information regarding chemicals should be reported beforehand.}

- Currently K-REACH is based on the selective registration of chemicals, and this cannot prevent mishaps such as the humidifier disinfectant cases. The law should be amended so that every known chemical that is distributed in more than 1 ton, and every new chemical distributed in more than 0.1 ton should be registered under K-REACH and Occupational Safety and Health Administration(OSHA).

- In Europe, every chemical product is sold after its toxicity is classified and labeled by Classification, Labelling and Packaging Regulation. Producers, importers, and merchandisers all have to report the toxicity classes and labels of chemicals to the government. This regulation applies to every chemical product, irrespective of the amount of distribution. The information is disclosed via websites, which clarifies and standardizes the toxicity class of each chemical. Unfortunately, K-REACH in Korea lacks this kind of measure. K-REACH and CCA should be revised so that the toxicity classification and label of every chemical product is reported and standardized clearly.

\section{All information about chemicals included in the product must} be disclosed to the consumers.

- REACH is a regulation of the European Union, adopted to improve the protection of human health and the environment from the harm that can be posed by chemicals.

- In principle, REACH applies to all chemical substances; not only those used in industrial processes but also in our day-today lives, such as cleaning products, paints, and articles such as clothes, furniture and electrical appliances. This means that REACH applies to almost every product used in our daily lives.

- But K-REACH applies to only liquid and gas products, excluding solid products. The goal of protecting children from daily chemical products thus seems far out of reach. This should be revised in order to find and manage solid products containing SVHCs.

The use of SVHCs should be reduced as far as possible.

- Although banning or granting permission may be a powerful regulatory measure, few chemicals are regulated in this way. It is true that there are some manufacturers that have to use dangerous chemicals. Northern European countries have been creating an 'undesirable substance list' to indicate chemicals which should be gradually reduced or even banned. Corporations have actively responded by referring to the list; for instance, they could take proactive action before a substance is banned, and tend to withdraw the use of listed chemicals for the sake of their brand image.

- REACH also identifies a 'candidate list' of substances of very high concern for authorization. Listed substances are not used for immediate legal obligations, but this works as a certain pressure on corporations.

- In Korea, the only legislation ensures the listing of regulated/ banned substances, which leaves all other chemicals freely used. We should not miss the crucial role of the 'candidate list' to secure the safer use of chemicals.

- The authorization process in Korea is quite different from that of REACH. While REACH uses a two-step regulatory process where manufacturers and importers prove their need to use SVHCs and then the government authorizes them after strict inspections, the authorization process by $\mathrm{K}-\mathrm{REACH}$ requires industry to apply for authorization from the government only for designated usage. This means that the legislation cannot use its regulatory potential to the full in the authorization process.

- As in European countries, chemicals used or contained in daily products, such as clothing, wallpaper, toys, and other products, should be known to consumers. Consumers have the right to know about the hazards of chemicals contained in a product, and revising K-REACH properly can enable this.

Toxic chemicals should be managed according to the level of toxicity.

- Carcinogens or reproductive toxic chemicals should not be hidden in the name of trade secrets, and regulatory measures should be taken automatically to protect consumers and workers from them, however, in Korea, registration of toxic chemicals follows an arbitrary management policy, not utilizing evidence-based toxicity classification standards. Previously, the CCA assigned certain toxic chemicals and applied its regulation only to those substances. The newly implemented K-REACH also follows this line by assigning 'harmful chemical substances' (i.e., a positive listing). OSHA also assigns a few substances to be regulated, but these lists still do not fully include known carcinogenic substances. Legislation should be revised to fully enable the standardization of a toxicity classification system with each substance being managed according to its classification as a default.

Rights over decisions regarding people's safety should be shifted to the people.

- The US Emergency Planning and Community Right-to- 
know Act (EPCRA) was created to help communities plan for emergencies involving hazardous substances. EPCRA requires emergency planning against hazardous chemicals by federal, state and local governments, with the decentralization principle that each community should participate in their own responses. Each state established a 'Local Emergency Planning Committee.' Industries are required to submit their management information about chemicals they use and plans for emergency responses in case of hazardous events. According to these reports, the committee can build their systematic plans for such events.

- Although Korea has in general followed the legislative structure of the US in CCA, the committee was excluded. The Ministry of Environment believed that civil participation in chemical management planning is not yet acceptable in Korea. Accordingly, Korean people have no choice but to receive information from individual corporations, which leads to information asymmetry, and the opportunity for effective community response is being lost. The creation of local committees to respond to daily harm caused by toxic chemicals should be based on CCA. Without proper lawful measures to ensure community participation, drawing community consensus on the issue will be impossible. The amendment of CCA is needed to guarantee civic participation.

The full right-to-know need to be realized for chemicals.

- In Korea, demand for disclosure of information on chemicals is being treated as if people are asking for disclosure of trade secrets, however, US legislation requires industry to fully disclose the total volume and list of chemicals used. A material safety data sheet (MSDS) is also disclosed to citizens. According to the CCA, corporations should fully disclose the results of chemicals statistics and emission levels. A detailed strategy and rules for enforcement need to be prepared to fulfill this principle. The CCA should be revised so that citizens can easily access material safety data sheets.

- There are places like Europe, Canada, and Taiwan that operate an MSDS disclosure policy with prior approval for trade secrets. These countries do not allow trade secrecy when the substances used exceed certain levels of toxicity. Only the law of Reagan's administration is the exception, to which Korea's current law has referred. The Korean OHSA act should thus be amended to introduce a prior approval system for trade secrets and to impose strict limitations on trade secrets for the sake of people's safety and health.

- Current law in Europe mandates that labels on product packages should disclose the substance's ingredients and the Chemical Abstract Service (CAS) registry number. In Korea, only cosmetics are required to disclose their entire ingredients. If the label shows the entire ingredients, it is much easier for consumers to access detailed information, and to consult experts. Currently, the only way to access this information is to look for an MSDS, and where of no MSDS has been disclosed, to ask the corporations for the disclosure. Institutional reform that enables people to easily access the information they need should be followed. OHSA should be revised so that labels on packages clearly show the ingredients of products.

\section{Conclusion}

We want a society where the population is not injured or killed for corporation profit. The tragedy caused by humidifier disinfectants should not happen again, and our community should be transformed into a safe place from all kinds of toxic chemicals. Heavy penalties should be imposed on irresponsible corporations, and proper compensation should be given to victims for suffering. Korean society should adopt more stringent standards for controlling chemicals.

\section{Conflict of Interest}

The authors have no conflicts of interest associated with material presented in this paper.

\section{ORCID}

Shinbum Kim http://orcid.org/0000-0002-1328-8221

Sanghyuk Im https://orcid.org/0000-0001-7243-5466

Correspondence: Sanghyuk Im 53 Sagajeong-ro 49-gil, Jungnang-gu, Seoul 02221, Korea

Tel: +82-2-490-2094

Fax: +82-2-490-2099

E-mail:imkooro@daum.net 